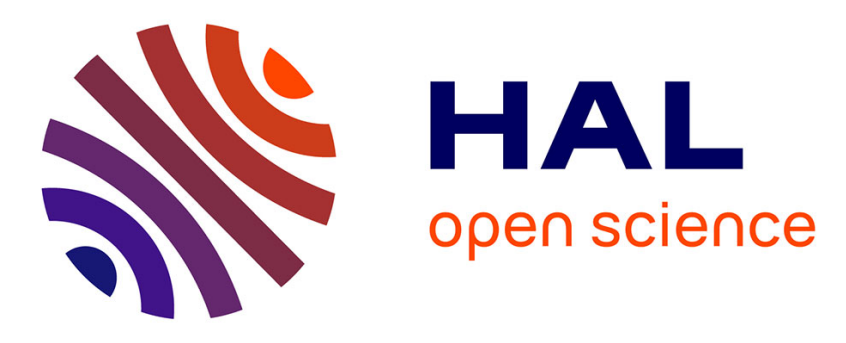

\title{
Enforcing Cooperative Storytelling: First Studies
}

Giulia Gelmini, Alessandro Cappelletti, Fabio Pianesi, Franca Rossi, Massimo Zancanaro

\section{To cite this version:}

Giulia Gelmini, Alessandro Cappelletti, Fabio Pianesi, Franca Rossi, Massimo Zancanaro. Enforcing Cooperative Storytelling: First Studies. International Conference on Advanced Learning Technologies, Aug. 30-Sept. 1, 2004, 2004, Joensuu, Finland. 5 p. hal-00190119

\section{HAL Id: hal-00190119 https://telearn.archives-ouvertes.fr/hal-00190119}

Submitted on 23 Nov 2007

HAL is a multi-disciplinary open access archive for the deposit and dissemination of scientific research documents, whether they are published or not. The documents may come from teaching and research institutions in France or abroad, or from public or private research centers.
L'archive ouverte pluridisciplinaire HAL, est destinée au dépôt et à la diffusion de documents scientifiques de niveau recherche, publiés ou non, émanant des établissements d'enseignement et de recherche français ou étrangers, des laboratoires publics ou privés. 


\title{
Enforcing Cooperative Storytelling: First Studies
}

\author{
Alessandro Cappelletti, Giulia Gelmini, Fabio Pianesi, Franca Rossi, Massimo Zancanaro \\ ITC-irst \\ \{cappelle|gelmini|pianesi|rossi|zancana@itc.it\}
}

\begin{abstract}
In this paper, we describe the first prototype of a system called StoryTable, aimed at supporting a group of children in the activity of storytelling. The system is based on a special multi-user touchable device (the MERL DiamondTouch) and it was designed with the purpose of enforcing collaboration between children. The paper discusses how the main design choices were influenced by the paradigm of cooperative learning and presents two observational studies to assess the effects of the different design choices on the storytelling activity.
\end{abstract}

\section{Introduction}

StoryTable ${ }^{1}$, aimed at supporting a cooperative storytelling activity among groups of children. The system was designed following the tenets of Cooperative Learning [1]. We also wanted to investigate the physical and social affordances of shared interactive displays.

StoryTable is a shared interface that displays a virtual world where children can move around objects and characters using their fingers as pointers. In this context, children are encouraged to tell, and record, a story about the world they have set on the display. The system allows the children to manipulate the scenarios and characters, while the story can only be verbal. The system is based on DiamondTouch [4], a multi-touch input technology that supports multiple, simultaneous users. We implemented a new GUI event system that

\footnotetext{
1 This work has been conducted in the context of the PEACH project funded by the local government of the Autonomous Province of Trento. We would like to acknowledge the contribution, in different phases of the research, of Adriano Freri, Franco Dossena, Marianna Nardon and Oliviero Stock. We would also like thank Paola Venturi for having introduced us to the NIH Methodology and the works on the Bear Family
}

allows the use of real multi-user actions like multi-user touches and multi-user drag-and-drop. We employed these kinds of actions as a way of enforcing cooperation among groups of children during storytelling activity. In particular, some crucial actions on StoryTable were implemented as multi-user actions in order to explicitly require an agreement.

We conducted two user trials to assess the design choices and to inform the next phases of the project. The studies suggest that, according to the claim of Cooperative Learning, cooperative storytelling can increase the level of engagement of less motivated children without affecting the involvement of the more active ones.

\section{Storytelling and Cooperative Learning}

Storytelling is a learning activity that allows children to develop skills such as creative problemsolving, collaborative learning, expressive design, the development of multiple forms of literacy, and the exploration of knowledge [7]. Among the attempts made so far at supporting storytelling, we can mention Sam, a tool developed at Media Lab [8], consisting of a 3-D animated virtual child that can pass physical toys back and forth to real children and can cooperate with children in constructing stories. KidPad, on the other hand, is a shared 2D drawing tool that incorporates a zooming interface [2], which allows children to bring their stories into life by zooming between drawing elements. KidPad's interfaces are designed in such a way to encourage children to explore the possibilities of collaborating, without forcing them to do so. Finally, the TellTale interface [1] explores the idea of providing ways of making the pieces of a story "tangible". TellTale is a caterpillar-like toy with five modular, colored body pieces on which children can record their own voices; once linked together the audio is played back in sequence. 
StoryTable differs from the mentioned works in many respects. First of all, it does not feature any kind of virtual companion, but directly targets (small) groups of children. Secondly, it aims at supporting them by actively enforcing cooperation while planning and building the story. In particular, key activities are explicitly synchronized; to this end, we relied on the notion of multi-user actions.

Cooperative Learning [1] is an instructional method that involves students working in teams to achieve a common goal. The emphasis is on the cooperation between the children that must be established and appropriately maintained in order for the methodology to display its benefits. To this end, a number of main tenets must be met [6]. First of all, a Positive interdependence must be established among students, so that they feel linked with group mates in such a way that they cannot succeed unless their group mates do and they feel that they must coordinate their efforts with the efforts of their group mates to accomplish the task. Positive interdependence has different facets; for example Positive Goal Interdependence, when the individual goals equal those of the group and Positive Resource Interdependence, when the resources needed to solve the problem have to be shared by the group members. Another condition is face-to-face promotive action, where individuals facilitate each other's efforts to achieve and complete task objectives in order to reach the group's goals. Finally, the performance of individual students must be assessed and the results provided to the individual and the group, fostering individual accountability/Personal Responsibility.

\section{StoryTable: Design and Implementation}

The system is based on DiamondTouch [4], a multitouch input technology that supports multiple, simultaneous users. DiamondTouch can distinguish who is touching and where. The device imposes some use constraints in order to work properly. In particular, it is necessary that each user maintains a physical contact with a rubber carpet. We have extended the DiamondTouch SDK in a Macromedia Flash library that recognizes events generated by multiple users acting together on the same GUI widget. This new event system comprises multiple-user touches and multiple-user drag-and-drops.

The StoryTable's interface has been designed according to the concept of ladybugs wandering around the table surface (see figure 1). One ladybug, the largest one, carries the backgrounds, the stages on which the story will be set - e.g., the woods, the medieval castle, and so on. Since the selection of the background is crucial for determining the story, the system forces agreement by requiring that background setting be done jointly by the children - e.g., through multiple-user touch events. Other ladybugs, similar in shape but smaller, carry the various elements that can be dragged onto the current background. A third type of ladybugs, different in shape, is meant to represent the audio snippets that will form the story. In order to load an audio snippet into these ladybugs, a child has to drag it into the recorder and then press the record button. Loaded audio ladybugs can be dragged onto a string of holes. When the children jointly touch a ladybug in a hole, it will play its content and the contents of the ladybugs in the following holes. The sequence of ladybugs in the holes becomes the story composed by the children.



Figure 1. The interface of the StoryTable on
the MERL's DiamondTouch.

The main objectives pursued with the design of the interfaces are related to the basic principles of cooperative learning. The story is composed collaboratively by both children (positive goal interdependence) using a limited number of Audio Ladybugs (positive resources interdependence); each contribution is clearly accountable to the child that recorded it (individual accountability). Each child is allowed to work on an individual level, but crucial operations have to be performed by both children simultaneously (appropriate use of collaborative skills and group processing).

From the point of view of improving story-telling capabilities, we expect that the limited portion of audio (no more than 30 seconds) each Ladybug can hold encourages children to reflect on the surface structure and the words they use to form their stories. Moreover, the possibility of reorganizing Audio Ladybugs should promote the reflection on the coherence among story segments. Finally, given that each Audio Ladybug can be re-recorded, children are encouraged to consider the role of each story unit in their narrative (similar conclusions have been drawn in [1].) 


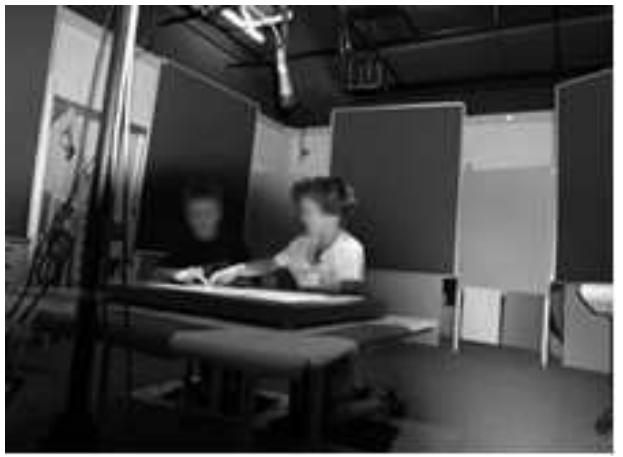

Figure 2. Children interacting with the StoryTable

\section{First Trial}

The purpose of the first trial was to assess the capability of children of different ages in recognizing and using the basic elements of the StoryTable interface.

Ten children were invited to play, in groups of two, with the StoryTable. As a control situation we set up a "low-tech" table with the same backgrounds used in the StoryTable but drawn on sheets of paper; puppets replaced the StoryTable characters and a standard tape recorder was proposed as a device to record the story.

The children were grouped according to age into five groups: (i) two 4 year-old girls; (ii) two 5 year-old boys; (iii) two 5 and 6 year-old girls; (iv) two 6 yearold girls; (v) one boy (7 years) and one girl (8 years).

Each pair of children was first introduced to each other and then spent 10-15 minutes playing with one experimenter to get to know each other. During this initial phase, they were asked about stories and storytelling. Then, they were given a short "hands-on" tutorial on the StoryTable that lasted a few minutes. The tutorial was organized as a quick and interactive introduction to the available operations. Each operation was first introduced by the experimenter and then the children were asked to repeat it. The children were taught that the StoryTable had two magic carpets each in a different color. Each child owned one of them and was given a sticker of the same color to put on her finger. The color corresponded to that of the shadow that would appear on each Audio Ladybug after the child had recorded it.

The children were then invited to play with the StoryTable for up to half an hour. In this phase, the experimenter intervened to help the children only when they had failed at three attempts to perform an action. Finally, the children were asked to play with the low- tech storytelling table and debriefed with a short interview.

There was a great amount of variation in the duration of the sessions, due to the fact that we did not force the children to play with the StoryTable for longer than they wanted. The durations were respectively: 11 minutes with 44 actions for the first group; 11 minutes with 233 actions for the second one; 5 minutes with 81 actions for the third; 35 minutes with 63 actions for the fourth; and 24 minutes with 162 actions for the fifth. As can be seen, it was not possible to reveal clear age-related patterns for duration and number of actions performed.

For the purpose of analysis, we collected the actions performed by the children in three groups. Multi-user actions were needed to select backgrounds (doubletouch), listen to the story (double-touch the first Audio Ladybug in the holes sequence) and change the ownership of an Audio Ladybug (multi-user drag-anddrop). Actions related to the management of the world comprised opening the Background Ladybug or the Characters Ladybug to choose a background and dragand-drop a character, respectively. The third group encompassed actions related to the storytelling, namely positioning the snippets on the microphone (single user drag-and-drop), recording and listening to an Audio Ladybug (single-user touches), and listening to the story (multi-user touch). The last and the first group partially overlap. Older children had a greater success rate and while younger children clearly understood the operations, the number of errors in performing them was very high. The most frequent causes of error were too fast or too slow double touches and faltering movements during drag-and-drop. Interestingly, the children were almost always able to self-diagnose the problem and to correct it in the next attempts.

The children did mind the constraints imposed by DiamondTouch. In particular, they easily managed to remain on the carpet while operating the StoryTable and to use their forefinger to touch the device. The only exception was noticed with the 4-year old children who were too small to reach the upper part of the table and in their attempts sometimes needed to lean on one hand, thus touching the table. Interestingly, they usually recognized their mistake and promptly recovered.

They always listened to an Audio Ladybug after having recorded it and they usually respected their partner's ladybugs (e.g. they asked to listen to the content rather than just double-clicking it). The 5-year girl of the third group fiercely claimed the last empty Audio Ladybug since her partner had already recorded three while she had only two. Finally, we noticed the 
unanticipated phenomenon of the affective relationship with the Audio Ladybugs. They always referred to them as "mine" and "yours" and they did not like to give their ladybugs to the partner (even if, when asked, they demonstrated they understood the procedure to do this, namely drag together the ladybug on the recorder). On the one hand, this hampered the children from freely using the Audio Ladybugs to build the story, while on the other this stimulated the shier children to take an active role.

The control sessions with the "low-tech" table were usually quite short. The children usually complained about the difficulty of audio recording. In most cases, one child in the group did most of the activities while the other barely participated.

\section{Second Trail}

The objective of the second trial was to understand better whether the StoryTable may be effectively used as a tool to support children in telling stories and to assess to what extent the interface, by forcing joint actions, can foster a collaborative behavior.

The same two 8-year old children from the first trial, a male and a female, were invited to participate in four further sessions with the StoryTable. The experimenter played a more active role, aimed at favoring a real storytelling activity. They fiercely suggested roles for characters, events of the story and sometimes even which sentences to record. Their involvement progressively decreased from the first to the last session; more precisely, the time taken by the experimenter for this kind of intervention was $70 \%$ of the total time in the first session, $44 \%$ in the second, $26 \%$ in the third and $5 \%$ in the last. To control the effect of the StoryTable, at the beginning of the first session we asked the children to tell an individual story each. We also asked the children to invent a joint story using puppets instead of the StoryTable at the beginning of the last session.

All the stories were evaluated using the NICHD Coding Scheme [3], a methodology specifically devised to measure the level of complexity in stories invented by children. For a story, three independent scores are computed, indicating respectively the story length, its cohesion and its structural richness. Length is measured in clauses and episodes. Narrative cohesion is estimated by means of a numerical scale from 0 to 11 ; each rate represents the highest level of cohesion achieved in the story. Furthermore, the narrative structure is measured verifying the presence of elements such as opening clauses, temporal setting of the story and so on. The structure is measured on a scale of 5 points.

Since the NICHD methodology was not designed to measure cooperation between the children, we decided to deal with this aspect by taking the different type of contributions made by the children during the entire interaction as a measure of their cooperation. To this end, we used the classification of language functions introduced by Halliday in [5]. According to Halliday, the way language is used in communication can be analyzed according to the different functions the speaker wants to perform while speaking. The most relevant functions for our purpose are the regulatory function that is used to regulate the behavior of others (e.g. "Get me water because I'm thirsty"), it can be positive when it is used to suggest or negative when used to blame; and the imaginative function enables children to relate to their environment using language to create a fantasy environment.

In the individual stories without the StoryTable, the girl was very verbose, telling a story of 12 episodes in 41 sentences which scored $9 / 11$ on the cohesion scale and $4 / 5$ on the structure scale. The boy told a very simple story of 5 episodes in 7 sentences which scored $3 / 11$ in cohesion and 4/5 in structure. The story told jointly without the StoryTable was invented almost exclusively by the girl; it comprises 12 episodes in 123 sentences and scored $10 / 11$ in cohesion and $5 / 5$ in structure. Regarding the StoryTable, we only considered the stories produced in the last two sessions since the role of the experimenters in the first two sessions were too strong. The story invented in the third session comprises 5 episodes ( 3 invented by the girl and 2 by the boy) in 12 sentences ( 10 recorded by the girl and 2 by the boy). The scores were $4 / 11$ for cohesion and $4 / 5$ for structure. After the session, the experimenters used the story recorded in the ladybugs to help the children point out problems in cohesion. The children then autonomously decided to re-record some parts of the story. The final version comprises 4 episodes ( 3 by the girl and 1 by the boy) in 8 sentences ( 5 by the girl and 3 by the boy). After the elaboration, the story scored $5 / 11$ for cohesion.

The story told in the last session with the StoryTable comprises 6 episodes ( 3 invented by the girl and 3 by the boy) in 13 sentences ( 10 recorded by the girl and 3 by the boy). The story scored $6 / 11$ in cohesion and 5/5 in structure. After the discussion with the experimenters and the elaboration performed autonomously by the children, the final version comprises 6 episodes ( 3 for each child) in 10 sentences ( 7 by the girl and 3 by the boy); the score for cohesion grew to $7 / 11$. 
Regarding their cooperation, the girl always led the interaction with 25 contribution of the imaginative type for the collaborative story with puppets and respectively $22,27,22$ and 21 contributions of this type in the sessions with the StoryTable. She performed very few heuristic and regulatory types of contributions and these were always positive. The boy did not perform any contribution of the imaginative type for the collaborative story with the puppets, while he performed 2 contributions of the heuristic type and 4 of negative regulatory type. During the StoryTable sessions, his contributions of the imaginative type grew respectively to $9,15,16$ and 11 . His preference for heuristic and negative regulatory contributions was still high.

The first important result is that working with the StoryTable helped the boy to be more involved (more contributions with respect to both his individual story and the puppet-based jointly story). On the other hand, the girl did not diminish her own level of engagement. The increased involvement of the boy is probably partly due to the novelty effect of the StoryTable and the attractiveness of the technology. Though he was often distracted, the boy was always kept involved by the girl who needed him to listen to the story (by multiuser actions) and was, therefore, motivated to have him involved. Furthermore, as already emerged from the first trial, both children developed a strong affective relation with their Audio Ladybugs; none of them ever lent their own Audio Ladybugs to the other, even when they were criticized for the contents and were explicitly requested to re-record it. It can be conjectured that this strong affective relationship also favored the boy's involvement.

The stories invented with the StoryTable were significantly shorter than the stories told with the puppets. This is most probably related to the limited number of ladybugs available. The paucity of resources, together with the affective relationship that the children showed with respect to these apparently improved the level of cooperation in the interaction. At the same time, being able to listen to the content of their recordings made the children more critical towards the form (i.e. false start, repetition and spelling errors were always pointed out by the children themselves without the intervention of the experimenters).

The stories invented with the StoryTable scored relatively lower than both the individual stories and the cooperative story with the puppets. This might be at least in part due to the cooperation itself, since inventing a story together is a significantly more complex activity than telling a story alone. Indeed, the cooperative story with the puppets was actually invented by the girl alone with very few contributions by the boy.

\section{Further work}

The main objective of the trials was to provide guidance for the next phases of development of the StoryTable. In particular, since the multi-user operations demonstrated to be a powerful means by which to stimulate cooperation, we plan to increase the number of these operations in the next version. In order to better assess the pedagogical value, we have already started a more extensive series of user studies with a local school.

\section{References}

[1] Ananny, M. (2002). Supporting Children's Collaborative Authoring: Practicing Written Literacy While Composing Oral Texts. In Proceedings of Computer-Supported Collaborative Learning, Boulder, Colorado, January, 2002.

[2] Benford S., Bederson B.B., Åkesson K., Bayon V., Druin A., Hansson P., Hourcade J.P., Ingram R., NealeH., O’Malley C., Simsarian K.T., Stanton D., Sundblad Y., Taxén G. Designing Storytelling Technologies to Encourage Collaboration Between Young Children. In Proceedings of ACM Conference on Computer Human Interaction, CHI2000.

[3] Bornstein M.H. (ed) The Bear Family. Cognitive Coding Handbook. Unpublished Manual .National Institute of Child Health and Human Development. Bethesda (MD)

[4] Dietz, P.H.; Leigh, D.L. DiamondTouch: A Multi-User Touch Technology. In Proceedings of ACM Symposium on User Interface Software and Technology (UIST). November, 2001

[5] Halliday, M. Explorations in the functions of language, London: Arnold.1973.

[6] Johnson, D., Johnson, R. Learning together and alone: cooperative, competitive, and individualistic learning. Boston: Allyn and Bacon. 1999.

[7] Peterson, C. \& McCabe, A. Developmental psycholinguistics: three ways of looking at a child's narrative. Plenum Press: New York.Preece, A. 1983.

[8] Ryokai, K., Vaucelle, C., Cassell, J. Virtual Peers as Partners in Storytelling and Literacy Learning. In Journal of Computer Assisted Learning 19(2). 195-208. 2003. 